\title{
Conventional PID and Modified PID Controller Design for Roll Fin Electro-Hydraulic Actuator
}

\author{
Fuat Alarçin ${ }^{1}$, Hakan Demirel ${ }^{2}$, M. Ertugrul Su ${ }^{1}$, Ahmet \\ Yurtseven ${ }^{1}$ \\ ${ }^{1}$ Faculty of Naval Architecture and Maritime, Y1ld1z Technical University, \\ Barbaros Bulvari 34349 Beşiktaş İstanbul, Turkey \\ E-mail: alarcin@yildiz.edu.tr, mesu@yildiz.edu.tr, ahmety@yildiz.edu.tr \\ ${ }^{2}$ Department of Marine Engineering Operations, Bulent Ecevit University, 67300 \\ Ereğli/Zonguldak, Turkey \\ E-mail: hakandemirel@ beun.edu.tr
}

\begin{abstract}
The aim of this study is to decrease a fishing boat's roll motion, which is adversely affected by disturbing hydrodynamic forces, by applying fin roll stabilizer. It is ensured that roll motion with nonlinear damping and restoring moment coefficients reaches the desired level by means of classical PID and modified PID algorithms. By Lyapunov's direct method, the key issue- stability which is needed during the course of sailing was examined considering initial conditions, and it was realized that the system was generally stable. Besides, NACA 0015 model was utilized for the fin roll stabilizer, and flow analysis was conducted by CFD method. According to the simulation results, when the same gains were practiced, modified PID controller algorithms were rather more efficient than conventional PID in the roll fin stabilizer system.
\end{abstract}

Keywords: modified PID control; fin stabilizer; Lyapunov direct method

\section{Introduction}

For many years, vessels have remained as a research subject for researchers as they lack fundamentals of stability despite meeting the requirements of current laws. It is known that a ship on route is likely to be off the stable zone due to disrupting hydrodynamic forces of a ship roll motion. Grim [1] modelled the roll equation using the gradual change in the restoring moment among the waves. In another study of his, he analyzed unstable roll equation in a more general equation form using Mathieu equation. 
Advanced studies on roll motion were carried out by Dalzell [2], and alternative damping models were put forward. Soliman and Thomson [3] solved the nonlinear differential equation of roll motion through $4^{\text {th }}$ level Runga-Kutta method. How damping effect of roll motion stability changed owing to disrupting forces and frequency was studied. Haddara and Wang [4] pointed out that quadratic damping model of speed for small fishing ships came up with good results. Taylan [5] studied a nonlinear roll motion model and the solution of this model through generalized Krylov-Bogoliubov asymptotic method on a time line. In this model, nonlinear restoring terms were considered as a $3^{\text {rd }}$ level polonium; likewise, nonlinear damping was regarded as a $2^{\text {nd }}$ level term. Taylan [6] studied on generalization of the nonlinear equation form indicating roll motion of a ship sailing amidst waves by means of Duffing method on frequency level. Surendran and Reddy [7] discussed the roll dynamics of a Ro-Ro ship taking into account many types of combination of loads in linear and nonlinear forms.

Safety of voyage has to be assured against the disrupting hydrodynamic effects of passengers as well as cargos, and roll amplitude has to be at an acceptable level. Therefore, a number of applications such as fin roll stabilizers and U-tube have been used in literature $[8,9]$.

Sgoppo and Persons [10] demonstrated that roll motion can be reduced by $35 \%$ through fin roll stabilizer system based on WMEC 901 class ship with $3^{\text {rd }}$ degree of freedom model. Surendran et al. [11] pointed out that nonlinear roll motion could be minimized with the fin roll stabilizer based on PID (ProportionalIntegral-Derivative) control algorithm considering a frigate warship. In this study, he acquired lift characteristics of the fin roll stabilizer stemming from hydrodynamic flow using CFD (Computational Fluid Dynamics). In simulations for different occasions, an $80 \%$ reduction in roll value was observed.

Guan and Zhang [12], who expressed nonlinear damping terms with the Backstepping Integrator theory, controlled the nonlinear fin roll stabilizer by means of PID and close loop algorithms by ignoring high level nonlinear terms. Ghassemiet al. [13] expressed that fin roll stabilizers are effective components in reducing roll amplitude out of wave movements. It was pointed out that lift forces occurring around the angle of attack and the fin roll stabilizer create a reversed moment. That's why he showed roll amplitude could be reduced using PID and Neural Network combination to control attack angle. Karakaş et al. [14] designed a controller based on Lyapunov method for fin roll damping systems in beam seas. The roll motion of the ship was considered as a single degree of freedom and $3^{\text {rd }}$ degree nonlinear terms were added to the model. It was mentioned that the likelihood of capsize was reduced to a considerable extent by means of the controller based on Lyapunov method. PID controllers' versions have been investigated by many researchers Alfaro et al. [24], Precup et al. [25], Hadlovska and Jajcisin [26]. 
In this paper, the problem of a nonlinear roll motion of fishing vessel is considered. Section 2 deals with mathematical model of nonlinear roll motion. Section 3 analyses stability of roll motion by Lyapunov's Direct Method. Section 4 describes the fin roll stabilizer system and classical PID and the modified PID controller. Nonlinear roll motion of a fishing boat, which will be capable of operating in the Black Sea and the Mediterranean Sea, was controlled by fin stabilizer system. Section 5 discusses simulation results.

\section{Mathematical Model of Nonlinear Roll Motion}

In order to ease to design mathematical model of ship motions, some important assumptions are made in modelling a fishing boat rolling motion, neglecting all other degrees of freedom of ships, xz-plane symmetry, rigid body and homogenous mass distribution. Considering some simplifications, the following nonlinear expression for the roll equation is obtained,

$$
(I+J) \ddot{\varphi}+B_{1} \dot{\varphi}+B_{2} \dot{\varphi}|\dot{\varphi}|+\Delta\left(c_{1} \varphi+c_{3} \varphi^{3}+c_{5} \varphi^{5}\right)=\omega_{e}^{2} \alpha_{m} I \cos \left(\omega_{e} t\right)-M_{f}
$$

where $\varphi, \dot{\varphi}, \ddot{\varphi}$ are angle, angular velocity and angular acceleration of roll motion, respectively. $I$ and $J$ are the mass moment of inertia and the added mass moment of inertia, respectively. $B_{1}, B_{2}$ are roll damping coefficients, $c_{1}, c_{2}, c_{3}$ are determined by restoring force coefficients and $\Delta$ is the weight displacement of the ship, $\omega_{e}$ is encounter frequency of the wave, $\alpha_{m}$ is the maximum wave slope, $M_{f}$ is the control moment of active fins. Dividing the equation (1) throughout by $(I+J)$,

$$
\ddot{\varphi}+b_{1} \dot{\varphi}+b_{2} \dot{\varphi}|\dot{\varphi}|+\Delta\left(c_{1} \varphi+c_{3} \varphi^{3}+c_{5} \varphi^{5}\right)=\frac{\omega_{e}^{2} \alpha_{m} I \cos \left(\omega_{e} t\right)}{I+J}-\frac{M_{F}}{I+J}
$$

Inertia moment arises due to the ship's reaction to a movement and it is proportional to the acceleration of motion. Added inertia moment is a reaction of sea water to the ship motion. These inertia values can be calculated depending on weight displacement of ship $(\Delta)$, breadth $(B)$ and the vertical distance of the center of gravity $(K G)$,

$$
(I+J)=\frac{\Delta}{12 g}\left(B^{2}+4 K G^{2}\right)
$$

The roll damping coefficient for a ship hull form has several contributions. These components are considered as skin friction of the hull, eddy shedding from the hull, free surface waves, lift effect damping and bilge keel damping. Theoretical and semi-empirical methods have been used to evaluate the roll damping by Ikeda 
et al. [15] and Ikeda [16]. A non-dimensional damping coefficient for different ship types is expressed as follows:

$$
\begin{aligned}
& B_{1}=\frac{2 a \sqrt{(I+J) \Delta G M}}{\pi} \\
& B_{2}=\frac{3}{4} b(I+J)
\end{aligned}
$$

These coefficients are directly related to a linear damping coefficient $B_{1}$ and a non-linear damping coefficient, $B_{2}$ represents quadratic drag [2]. The nondimensional damping coefficients for fishing boat were obtained as follow $(a=0.1$, $b=0.0140$ ). The curve for righting arm has been represented by the polynomial,

$$
M(\varphi)=c_{1} \varphi+c_{3} \varphi^{3}+c_{5} \varphi^{5}+\ldots
$$

where $c_{1}>0, c_{3}<0, c_{5}>0$. The roll restoring moment coefficients are defined by ref. [6]

$$
c_{1}=\frac{d(G Z)}{d \phi}=G M \quad c_{3}=\frac{4}{\phi_{v}^{4}}\left(3 A_{\phi v}-G M \phi_{v}^{2}\right) \quad c_{5}=-\frac{3}{\phi_{v}^{6}}\left(4 A_{\phi v}-G M \phi_{v}^{2}\right)
$$

Angle of vanishing stability $\phi_{v}$, area under the $G Z$ curve $A_{\phi v}$, and dynamic characteristics of the $G Z$ curve such as metacentric height $G M$. Based on the above-mentioned coefficients, numerical calculations were carried out for a fishing boat, whose body plan is given in Fig. 1.

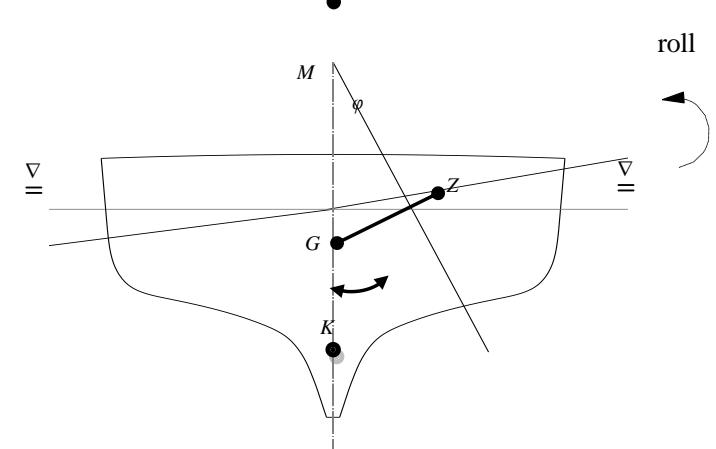

Figure 1

Body plan of the fishing boat

The righting arm curve is a graphical representation of the fishing boat's stability in Fig. 2 [17]. From this figure, it can be seen that Hydrodynamic lift effect develops in an approximately linear manner with an increasing angle of attack. 
The area under the curve is an indication of the fishing boat's ability to counter the capsizing moments acting on the boat.

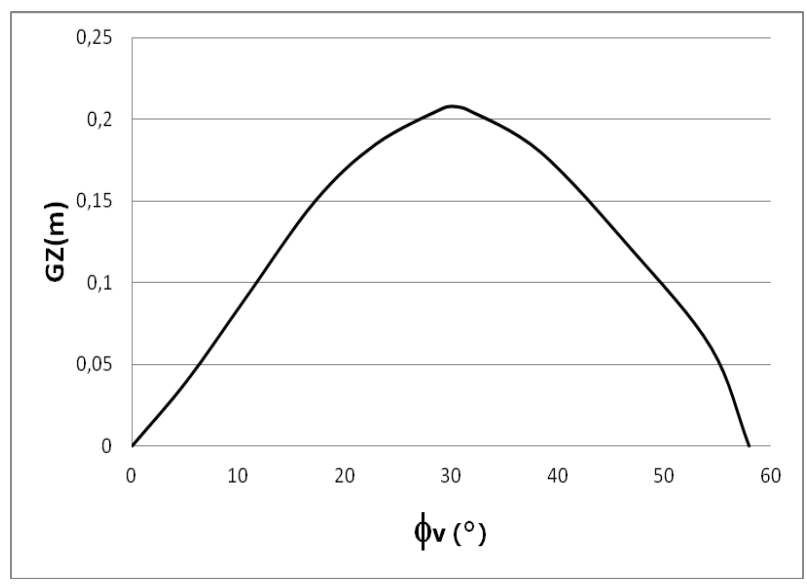

Figure 2

Righting arm curve of fishing boat

Due to the influences of high wave frequency, ships sailing on the sea produce undesirable roll motion. It is expressed the wave moment to consist of the encounter frequency as,

$$
M_{w}=\omega_{e}^{2} \alpha_{m} I \cos \left(\omega_{e} t\right)
$$

$\omega_{e}=\omega_{w}-\frac{\omega_{w}^{2}}{g} V \cos \left(\mu_{w}\right)$

$M_{w}$ is the wave moment, $\omega_{e}$ is the encounter frequency of the wave, $\omega_{w}$ is the wave frequency, $\alpha_{m}$ is the maximum wave slope, $\mu_{w}$ is the wave encounter angle of the ship. It can be envisaged that the wave excitation will depend not only on amplitude and frequency of the waves but also on encounter angle and speed.

\section{Stability Analysis of Roll Motion by Lyapunov's Direct Method}

A fishing boat is called stable when it has enough positive stability to counter the external forces generated by current weather, fishing conditions and it will return to its upright position [18]. Lyapunov's Direct Method was used for stability analyses by Ozkan [19]. This is a very powerful and applicable technique since it 
does not require any knowledge about the explicit solutions of the equations. By using state variables of equation (1),

$$
\begin{aligned}
& \dot{\varphi}=\dot{\varphi}_{1}=\varphi_{2} \\
& \dot{\varphi}_{2}=-\left(\omega_{0}^{2} \varphi_{1}+m_{3} \varphi_{1}^{3}+m_{5} \varphi_{1}^{5}\right)-\left(b_{1} \varphi_{2}-b_{2} \varphi_{2}\left|\varphi_{2}\right|\right)
\end{aligned}
$$

Lyapunov function $V_{x}$ satisfying

- $\quad V_{x}>0$ positive definite and $V(0)=0$

- $\quad \frac{d V(\vec{x})}{d t} \leq 0$

- $\quad V(x) \rightarrow \infty$ as $\|x\| \rightarrow \infty$

Lyapunov second method will be used to test the system stability.

$$
\dot{V}(t)=\frac{d V(\vec{x})}{d t}=\nabla V^{T} \overrightarrow{\dot{x}}
$$

If symmetric coefficients are assumed equal to zero, derivative of the Lyapunov function is negative. Lyapunov function is obtained depending on the non-linear roll damping coefficient. If this value is smaller than zero, non-linear roll motion can be said to be stable.

$$
\begin{aligned}
& \dot{V}(x)=-\varphi_{2}^{2}\left(b_{1}+b_{2}\left|\varphi_{2}\right|\right)<0 \\
& V(x)=\omega_{0}^{2} \frac{\varphi_{1}^{2}}{2}+m_{3} \frac{\varphi_{1}^{4}}{4}+m_{5} \frac{\varphi_{1}^{6}}{6}
\end{aligned}
$$

\section{Controller Design for Roll Fin Actuator}

The objective of the control is to generate the input current such that the angular position of the control fin is regulated to the desired position. The motion of a ship can be affected by fin actuators that impart forces and moments. Actuators play a very important role in the control system structure. When the roll fin stabilizers attack to the fluid, it can bee seen that the lifting force caused by the rotation and the angle of attack occurs on the surface of fins. The lift force and the lift in nondimensional form are as in the following form in Fig. 3 [8], 


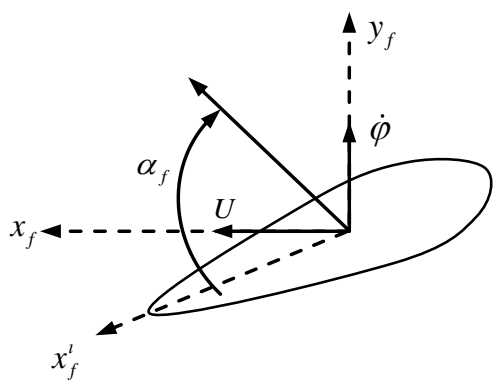

Figure 3

Ship roll fin stabilizer

$L=\frac{1}{2} \rho V A_{F} C_{L}$

$C_{L}=\frac{L}{0.5 \rho V^{2} A_{F}}$

where $L$ lifting force $(\mathrm{N}) ; \rho$ density of fluid $\left(\mathrm{t} / \mathrm{m}^{3}\right) ; A_{F}$ fins area $\left(\mathrm{m}^{2}\right) ; C_{L}$ fins lift coefficient (lift coefficient/rad); $V$ the ship speed $(\mathrm{m} / \mathrm{s})$. General formulas of fin roll stabilizer are expressed as the following equations:

$M_{F}=\rho V^{2} A_{F} C_{L} I_{F}\left(\alpha_{F}+\frac{\dot{\varphi}}{v} I_{F}\right)$

where $M_{F}$, fin roll stabilizer moment; $I_{F}$ the fins force arm; $\alpha_{F}$ attack angle. The electro-hydraulic system dynamics of fin stabilizer system are assumed to be governed by

$\dot{\alpha}_{F}+t_{1} \alpha_{F}=t_{2} u_{F}$

where $\alpha_{F}$ is the actuator output (actual fin angle), $u$ is the input to the electrohydraulic systems. The hydraulic control model presented in Fig. 4. Conrol surfaces are commanded by hydraulic machinery that implement the action demanded by controller.

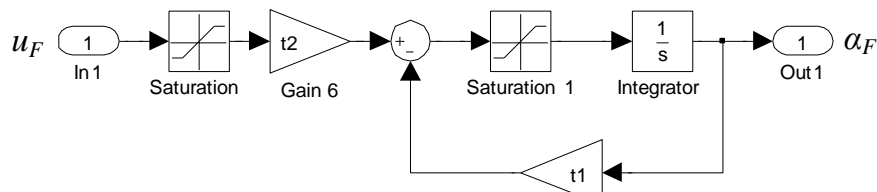

Figure 4

Block diagram of fin stabilizer system

As can be seen in Fig. 4, a saturator has been intermitted between the controller and the fin actuator. 
This element models the saturating behaviour of the controller. The foil motion is constrained to move within certain maximum angle.

$$
-\alpha_{F \max } \leq \alpha_{F} \leq \alpha_{F \max }
$$

The results of hydrodynamic lift coefficient in function of attack angle of fin and roll angle of ship are presented in Fig. 5.

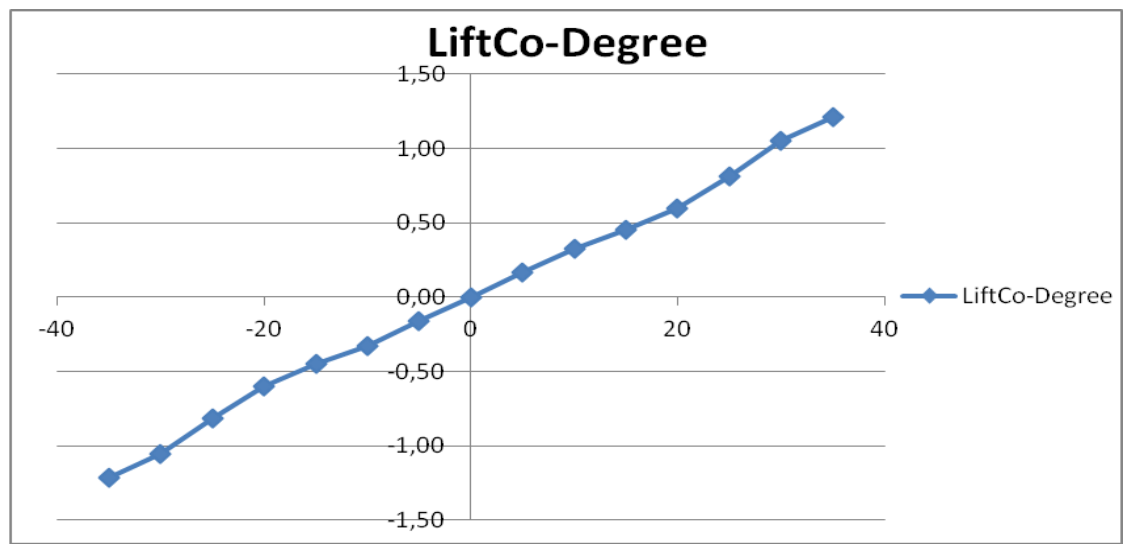

Figure 5

Lift coefficient

Computational fluid dynamics analysis has been carried out with Star CCM + package software, via 8 Parallel Processor and 24 GB of RAM hardware configuration. Preprocessing, running and finishing parts were integrated in the program. At the time of Preprocessing, Trimmer, Surface Remesher and Prism Layer Masher solution mesh properties were executed simultaneously. Hexahedral meshes analyses were conducted. Variations with 170000, 970000 and 1500000 cells were generated respectively for our three dimensional model and afterwards, the solution continued with the one having 970000 cells 2900000 surface via mesh independence. A sample case of free surface shape around fin is presented in Fig. 6.
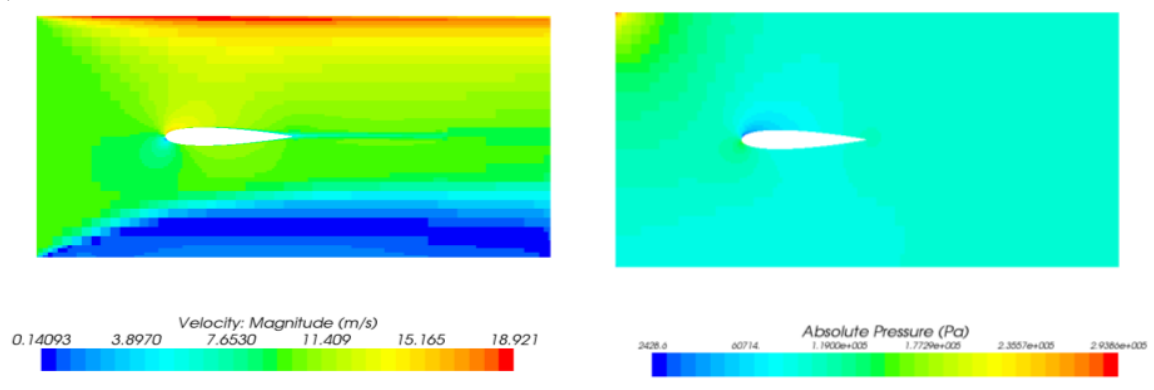

Figure 6

Velocity and pressure gradient cross section (attack angle $+30^{\circ}$ ) 
We considered only a magnitude constraint for the mechanical angle of the fins as $30^{\circ}$. Segregated flow, Reynolds averaged Navier Stokes and k- $\varepsilon$ turbulence model were used as the solvers for running process. Convergence conditions were approximately $1 E-5\left(10^{-5}\right)$. Running was carried out in parallel with 8 cores. During the final process, along with the velocity and pressure gradients, the lift force coefficient was directly taken from the model. This coefficient was obtained depending on fin roll stabilizer's attack angle (from $-30^{\circ}$ to $+30^{\circ}$ ).

\subsection{Conventional PID Controller}

The parameters of PID controller lead to different effects on system characteristics. The proportional block provides an overall control action, and the integral block reduces steady-state errors. On the other hand, the derivative block improves transient response. The basic elements of a PID controller for a ship roll motion control system are shown in Fig. 7 [20].

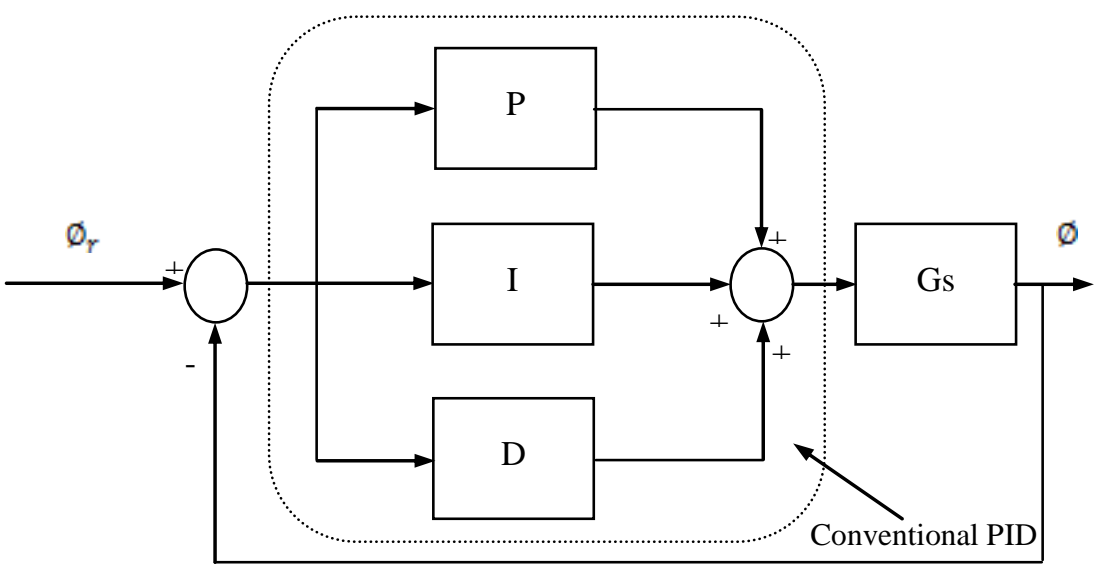

Figure 7

Closed loop system with conventional PID controller

Generally, transfer function of classical PID controller is given below:

$G_{p i d}(t)=K_{p}\left[e+\frac{1}{\tau_{i}} \int d(t)+\tau_{d} \frac{d e(t)}{d t}\right]$

Where $\tau_{i}=\frac{K_{p}}{K_{i}}, \tau_{d}=\frac{K_{d}}{K_{p}}$ and $e$ is the error between the reference and the output of a system, $\tau_{i}$ is the integral time, $\tau_{d}$ is derivative time. $K_{p}, K_{i}$ and $K_{d}$ are 
proportional, integral and derivative gains, respectively. The conventional PID controller is the simplest form of controllers that utilize the derivative and integration operations in the compensation of control systems. Thanks to its flexibility, it is easier to use this controller in many applications and many control problems [21, 22, 23, 24, 25, 26, 27 and 28]. The model of closed loop system with modified PID is shown in Fig. 8.

\subsection{Modified PID Controller}

The position of integral action which affects the difference of reference signal and feedback signal has remained unchanged on forward path. However, derivative and proportional actions have moved on feedback path to affect only the output signal. The objective is to force the system's output to follow a given bounded reference value.

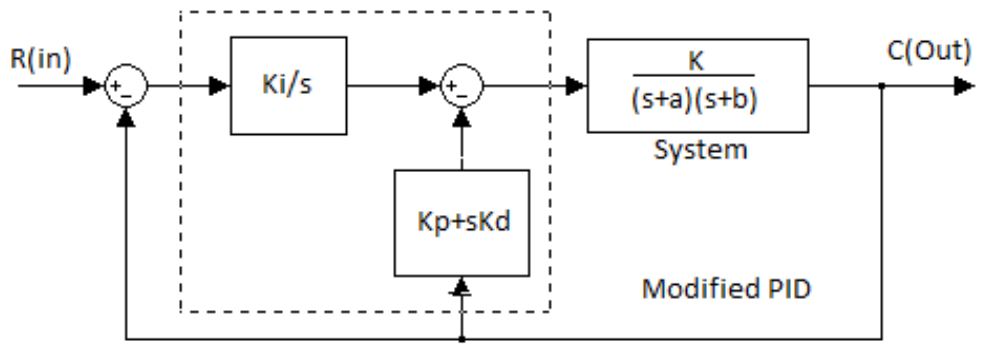

Figure 8

The model of closed loop system with modified PID controller

The modified PID controller can be indicated as follows:

$G_{c}(s)=\frac{K_{i}-s K_{p}-s^{2} K_{d}}{s}$

Transfer function of closed loop system is given below:

$$
\frac{C(s)}{R(s)}=\frac{K_{i} K}{s^{3}+s^{2}(a+b)+s\left(a b+K_{i} K_{d} K\right)+K_{i} K_{p} K}
$$

There are two zeros in the system with conventional PID controller. It is hard to adjust the system response due to these zeros. Their effect occurs as earlier peak or higher overshoot. The proposed modified PID controller gets over these effects and ameliorates the system response by adding proportional and derivative blocks of PID on feedback path instead of on forward path. Therefore, better solution of system response is achieved in modified PID in comparison with conventional PID. 


\section{Simulation}

In control application, mathematical model was presented to perform numerical simulations of different scenarios, and to obtain the performance of the fin stabilizer system. These numerical simulations were applied with Matlab simulink program. The fishing boat and the fin (NACA 0015) particulars are shown in Table 1.

Table 1

The fishing boat and the fin (NACA 0015) particulars

\begin{tabular}{|c|c|c|}
\hline Principal Particulars & Symbol & Parameter \\
\hline Length between perpendiculars & $L_{b p}$ & $20 \mathrm{~m}$ \\
\hline Breadth & $B$ & $5.714 \mathrm{~m}$ \\
\hline Depth & $D$ & $3.2 \mathrm{~m}$ \\
\hline Draught & $T$ & $2.285 \mathrm{~m}$ \\
\hline Displacement & $\nabla$ & $119.34 \mathrm{~m}^{3}$ \\
\hline Metacentric height & $G M$ & $0.57 \mathrm{~m}$ \\
\hline Vertical center of gravity & $K G$ & $2.4 \mathrm{~m}$ \\
\hline Block coefficient & $C_{B}$ & 0.457 \\
\hline Service speed & $V$ & $10 \mathrm{knot}$ \\
\hline Fins area & $A_{F}$ & $2.5 \mathrm{~m}^{2}$ \\
\hline Fins lift coefficient & $C_{L}$ & 0.65 \\
\hline Vanishing angle of stability & $\phi_{v}$ & $58^{0}$ \\
\hline
\end{tabular}

Non-dimensional damping and restoring moment coefficients for fishing boat are expressed in Table 2.

Table 2

Non-dimensional damping and restoring moment coefficients for fishing boat

\begin{tabular}{|l|l|l|l|l|}
\hline $\mathrm{b}_{1}$ & $\mathrm{~b}_{2}$ & $\mathrm{~m}_{1}$ & $\mathrm{~m}_{3}$ & $\mathrm{~m}_{5}$ \\
\hline 0.069 & 0.010 & 1.204 & -1.80 & 0.61 \\
\hline
\end{tabular}

The flow chart of MPID control system is displayed in Fig. 8. The simulation results for fin roll stabilizer system show roll angle, roll velocity and phase diagram in Figs. 9, 10 and 11. Comparisons of the control performance were made between conventional PID and the MPID controllers. $K_{p}, K_{i}$ and $K_{d}$ control values were obtained by trial method. The values of PID gains $K_{p}=0.2145, K_{d}=1.2288$, $K_{i}=2.89$, ensured good roll reduction. The modified PID control response of the fin roll stabilizer is better than PID control. 


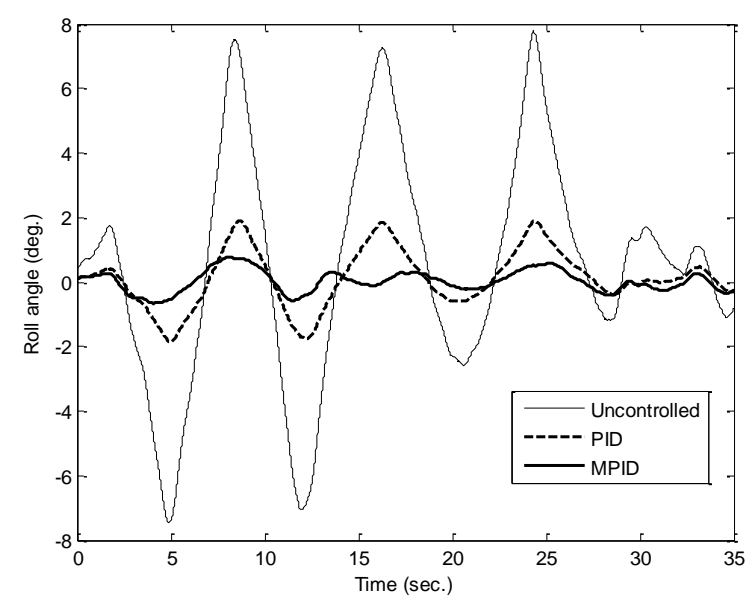

Figure 9

Comparison of roll angle response

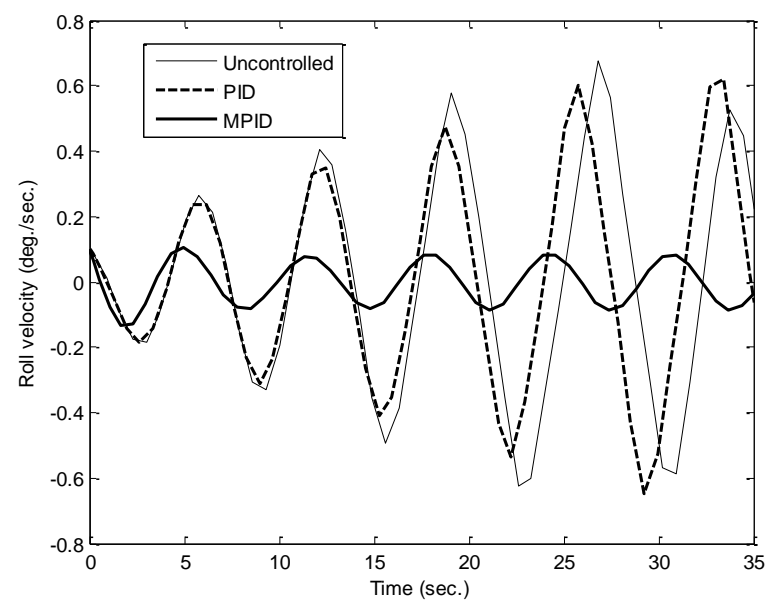

Figure 10

Comparison of roll velocity response 


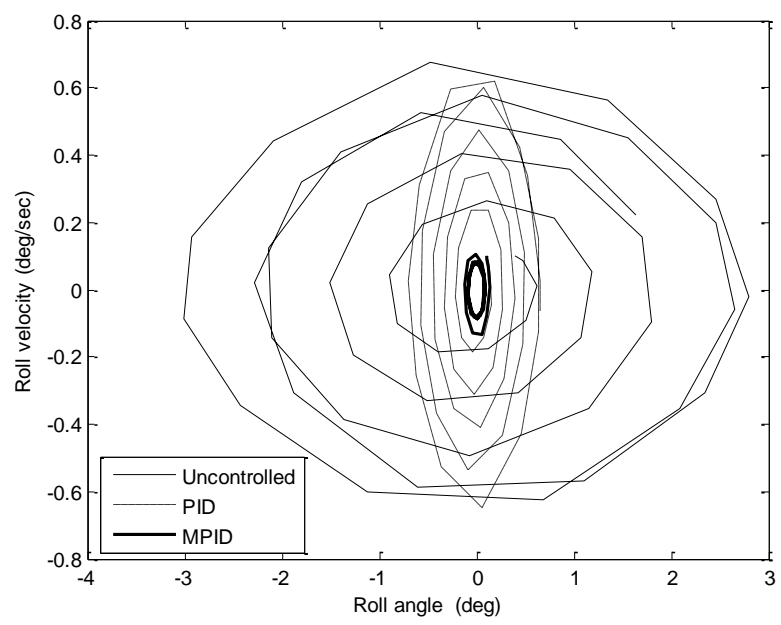

Figure 11

Comparison of phase diagram

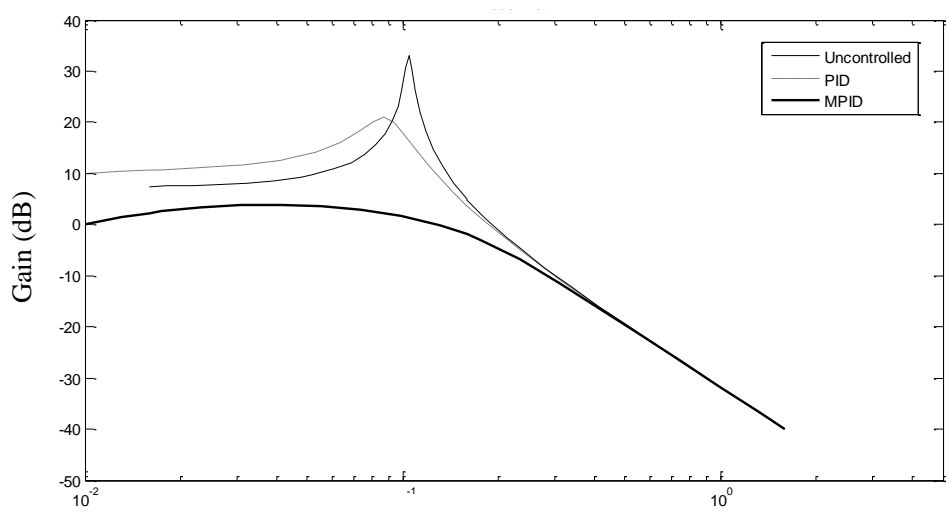

Frequency $(\mathrm{Hz})$

Figure 12

Frequency response of the roll motion for uncontrolled, PID and MPID

Since the aim of the controller was to control the roll motion, the improvement has been realized particularly around $1.1 \mathrm{~Hz}$ at low frequencies. This is also demonstrated by plotting the frequency response of controlled and uncontrolled body bounce acceleration in Fig. 12.

The comparison of the two controllers is presented in Table 3, which shows roll angle and roll velocity. The settling time for uncontrolled is longer compared to the time for settlement of MPID. 
Table 3

Performance Comparisons

\begin{tabular}{|l|l|l|}
\hline Controller & Max. roll angle (deg.) & Max. roll velocity (deg./s) \\
\hline Uncontrolled & $7.8^{0}$ & 0.7 \\
\hline PID & $1.9^{0}$ & 0.6 \\
\hline MPID & $0.7^{0}$ & 0.1 \\
\hline
\end{tabular}

\section{Conclusions}

This paper introduces a mathematical modeling, and examines controlling of nonlinear roll motion by applying fin stabilizer system. Nonlinear restoring and damping moment coefficients are computed by means of empirical equations. Nonlinear roll motion stability of fishing boat is examined through Lyapunov direct method. In the course of the simulation, it is accepted that the control gains receive the same values for PID and MPID algorithms. According to the results of the simulation, it is notable that MPID controller has shown a considerable amelioration in roll magnitude about $91 \%$. The performance of MPID controller performance has been $15.4 \%$ greater than conventional PID as shown in Table 3.

\section{References}

[1] O. Grim: schwingungen, Stabilitat und Sicherheit in Seegang, Schiffstechnik (1952) pp. 85-100

[2] J. F. Dalzell: A Note on the Form of Ship Roll Damping, Journal of Ship Research, Vol. 22(3) (1978) pp. 178-185

[3] M. Soliman and J. M. T. Thompson: Transient and Steady State Analysis of Capsize Phenomena, Applied Ocean Research, 13 (1991) pp. 82-92

[4] M. Haddara and Y. Wang: Parametric Identification of Maneuvering Models for Ships, Int. Shipbuild. Programs, 445 (1999) pp. 5-27

[5] M. Taylan: Solution of the Nonlinear Roll Model by a Generalized Asymptotic Method, Ocean Engineering, Vol. 26 (1999) pp. 1169-1181

[6] M. Taylan: The Effect of Nonlinear Damping and Restoring in Ship Rolling, Ocean Engineering, Vol. 27 (2000) pp. 921-932

[7] S. Surendran and R., Venkata Ramana Reddy: Roll Dynamics of a Ro-Ro Ship, International Ship Building Progress, Vol. 49, No. 4 (2002) pp. 301320

[8] T. Perez and G. C. Goodwin: Constrained predictive Control of Ship Fin Stabilizers to Prevent Dynamic Stall, Control Engineering Practice 16, (2008) pp. 482-494

[9] C. Holden and T. I. Fossen: A Nonlinear 7-DOF Model for U-Tanks of Arbitrary Shape, Ocean Engineering 45 (2012) pp. 22-37 
[10] J. N. Sgobbo and M. Parsons: Rudder/Fin Roll Stabilization of the USCG WMEC 901 Class Vessel, Marine Technology, 36 (1999) pp. 157-170

[11] S. Surendran, S. K. Lee and S. Y. Kim: Studies on an Algorithm to Control the Roll Motion Using Active Fins, Ocean Engineering 34 (2007) pp. 542551

[12] W. Guan and X. K. Zhang: Concise Robust Fin Roll Stabilizer Design Based on Integrator Backstepping and CGSA, Systems and Control in Aeronautics and Astronautics (ISSCAA) $20103^{\text {rd }}$ International Symposium on , Vol. 3, 8-10 June 2010, pp. 1392-1397

[13] H. Ghassemi, F. H. Dadmarzi, P.Ghadimi and B. Ommani: Neural Network-PID Controller for Roll Fin Stabilizer. Polish Maritime Research 2(65) Vol. 17, (2010) pp. 21-30

[14] Ş. C. Karakas, E. Uçer and E. Pesman: Control Design of Fin Roll Stabilization in Beam Seas Based on Lyapunov's Direct Method, Polish Maritime Research 2 (73), Vol. 19 (2012) pp. 25-30

[15] Y. Ikeda, Y. Himeno and N. Tanaka: New York A Prediction Method for Ship Roll Damping, Report No. 00405 of the Department of Naval Architecture, University of Osaka Prefecture (1978)

[16] Y. Ikeda: Prediction Methods of Roll Damping of Ships and their Application to Determine Optimum Stabilization Devices, Marine Technology, Volume 41, Number 2, 1 April 2004, pp. 89-93(5)

[17] M. Aydın and H. Akyıldız: Assessment of the Intact Stability Characteristics of the Fishing Boats Suitable for Turkish Water. ITU publications Vol. 4 (2005) No. 6

[18] M. A. S. Neves., N. Perez and L. Valerio: Stability of Small Fishing Vessels in Longitudinal waves, Ocean Engineering, 26 (1999) pp. 13891419

[19] I. R. Ozkan: Lyapunov's Direct Method for Stability Analysis of Ships, ITU, $\mathrm{PhD}$ dissertation (1977)

[20] K. Ogata: Modern Control Engineering, Prentice-Hall, $4^{\text {th }}$ Edition, New Jersey (1990)

[21] T. Hagiwara, K. Yamada, Y. Ando, I. Murakamı, S. Aoyama and S. Matsuura: A Design Method for Modified PID Control Systems For Multiple-Input, multiple-Output Plants To Attenuate Unknown Disturbances, World Automation Congress, Vol. 7 (2010) pp. 1-6

[22] A. Visioli: Modified Anti-Windup Scheme for PID Controllers. IEE Proc.Cont. Theory App., Vol. 150, No. 1 (2003) pp. 49-54

[23] K. Yamada, N. Matsushima and T. Hagiwara: A Design Method for Modified PID Controllers for Stable Plants and Their Application, ECTI 
Transactions on Electrical Eng., Electronics and Communications Vol. 5, No. 1 (2007) pp. 31-40

[24] V. M. Alfaro, R. Vilanova, O. Arrieta: Robust Tuning of Two-Degree-ofFreedom (2-DoF) PI/PID-based Cascade Control Systems, Journal of Process Control, Vol. 19, No. 10 (2009) pp. 1658-1670

[25] R. E. Precup, S. Preitl, E. M. Petriu, J. K. Tar, M. L. Tomescu, C. Pozna: Generic Two-Degree-of-Freedom Linear and Fuzzy Controllers for Integral Processes, Journal of The Franklin Institute, Vol. 346, No. 10 (2009) pp. 980-1003

[26] W. Ji, Q. Li, B. Xu, D. Zhao, S. Fang: Adaptive Fuzzy PID Composite Control with Hysteresis-Band Switching for Line of Sight Stabilization Servo System, Aerospace Science and Technology, Vol. 15, No. 1 (2011) pp. 25-32

[27] A. Hadlovska, S. Jajcisin: Predictive Control Algorithms Verification on the Laboratory Helicopter Model, Acta Polytechnica Hungarica, Vol. 9, No. 4 (2012) pp. 221-245

[28] F. Tahri, A. Tahri, A. Allali, S. Flazi, The Digital Self-Tuning Control of Step a Down DC-DC Converter, Acta Polytechnica Hungarica, Vol. 9, No. 6 (2012) pp. 49-64 